\title{
Hermenéutica e historicismo
}

\author{
María Rosa Palazón
}

\section{as concepciones ahistóricas del conocimiento}

Desde épocas paleolíticas, según prueban testimonios, el ser humano ha manejado la noción del universo en cambio o devenir. Pensando el tiempo colectivo como movimiento en el espacio, especialmente en relación con los astros, pudo establecer la ubicación de las cosas y medir la recurrencia cíclica del día y la noche, de semanas, meses, años, siglos, de estaciones, así como fechas del nacimiento de animales o del despuntar de plantas, del florecer o desarrollarse y del marchitarse o morir. La útil medición no contempla, sin embargo, el modo como vivimos los cambios, a saber, como pasado que ha dejado de ser, y un efímero e inasible presente en tránsito hacia un anticipado futuro que no es.

1. Preocupados por tales enigmas y sus consecuencias en el ámbito del conocimiento, los griegos de la antigüedad clásica y sus sucesores inmediatos se debatieron en un dilema: o todo lo existente cambia -está en movimiento, decían-, tanto el estímulo como su perceptor, y, por lo tanto, quererlo fijar cognoscitivamente es un error, siendo las opiniones en contrario la ilusión de muchos que no se reconocen como una falible medida de todas las cosas, afirmaron los sofistas y los escépticos, en su fallido intento de relativizar absolutamente el conocimiento; o en el ámbito del ser, no de la existencia, todo persiste y nada cambia: la información sensorial refiere una realidad menor, insignificante, vacía en comparación con lo permanente o esencial. Para los que hicieron suyo este cuerno del dilema, no hay ciencia de lo transitorio, siendo el tiempo un pálido reflejo "móvil" de la subsistencia. Henos ante los presocráticos destacando algo como origen eterno, o causa final que no cambia, o a un Platón que disecciona los conceptos, ele- 
mentos últimos del logos, como si refirieran conjuntos biyectivos de cualidades que permanecen, de inmutables propiedades inespaciales e intemporales que la razón abstrae a partir de los accidentes, las indicaciones perentorias o "sombras" que aprehendemos mediante los sentidos, la cárcel corporal a que estamos encadenados. Bajo esta perspectiva, la realidad -el ser en oposición al existir-es conforme a las ideas.

En Identidad y diferencia, Heidegger -que ejerció una gran influencia en Gadamer-sostiene que el principio de identidad que defendió Parménides no sólo es un presupuesto lógico, sino que determinó una onto-teo-logía que asimila el modo de pensar y de ser (de los entes). ${ }^{1}$ Después de este gran suceso -Ereignis- epistemológico se estableció un principio de igualdad: lo pensado o dicho, es. La razón lee, permítaseme resumir con la terminología de Foucault, las "signaturas" como las propiedades inmutables del ser. Esta hipotética identidad, o correspondencia entre signos y cosas, fue el criterio para la objetividad y para la verdad y la falsedad.

2. El mundo o lo existente continuó siendo visto como un despliegue de lo mismo, instaurándose la tesis determinista de que unos antecedentes acaban en las mismas consecuencias: como el exceso de algo genera su opuesto, decían los griegos, los ricos están muy amenazados por la pobreza. La ordenación de los hechos en cadenas sucesivas -de causas a efectos- alcanzó un triunfo espectacular cuando Galileo y Newton, entre otros, completaron las leyes sobre el estado estático de la materia con las del dinámico. Las explicaciones nómicas, o basadas en leyes, establecen que las cosas cambian. Este modelo o paradigma explicativo que se propuso como único -o como el método científico - consta de una fase nomotética, o de establecimiento de leyes, y otra nomológica o deductiva, que las aplica en las explicaciones. Ambas fases se basaron en la verificación empírica como principio insoslayable.

Según este método, la explicación consta de hipótesis generales, que al ser comprobadas, lo que incluye que se fije la variación de su probabilidad de cumplimiento (o su cobertura), adquieren el rango de leyes inamovibles. Una formulación nómica no sirve únicamente para explicar los hechos, sino, además, para predecirlos y posdecirlos. Es como un línea recta que traza. mos a partir de un punto -el presente-, hacia la izquierda -el pasado-y hacia la derecha -el futuro-: dadas unas condiciones, con una probabilidad $x$ se produce, se produjo y se producirá un resultado. Notemos que para explicar el cambio de las cosas se fijan las leyes:

${ }^{1}$ Cf. Martin Heidegger, Identidad y diferencia. Trad. de Helena Cortés y Arturo Leyte. Barcelona, Antrophos, 1988. (Autores, Textos y Temas de Filosofia) 
Si admitiésemos leyes que estuvieran sujetas a cambio, nunca podríamos explicar el cambio con leyes, equivaldría a que el cambio es simplemente milagroso. Y sería el fin del progreso científico; porque si llegasen a hacerse observaciones inesperadas, no habria necesidad de revisar nuestras teorias: las hipótesis ad hoc de que las leyes habían cambiado, lo "explicaría" todo. ${ }^{2}$

El punto de vista del monismo metódico busca y mide la repetición del cambio, su redundancia. Lo irónico del caso es que este método, al eregirse como el único válido para conocer la pretensa determinación universal, o cualquier realidad, por dificil de investigar que sea, y su exclusión de pre. guntas sobre las diferencias que no se repiten según una medible variación de la probabilidad, viola su propio principio de verificación empírica, porque haria falta un dios que estableciera que todas las relaciones, entre unas condiciones y un resultado que hubo, hay y habrá, son formulables en leyes, y haría falta tener un punto de vista inalterable que excluyera los cambios únicos o al azar, o bien, tal y como son experimentados, es decir, como mudables recuerdos, como acontecimiento en tránsito hacia el pasado y como expectación futura.

3. Cuando se miró la realidad como un holon o sistema -o relación de elementos tal, que cualquier alteración de uno altera (más o menos) el todose vislumbró como un conjunto estrecho de enlaces con su propia unicidad. Una aclaración. La regla de un enfoque holista es la "anticipación de la perfección": ${ }^{3}$ sólo es comprensible lo que tiene una unidad de sentido. Gadamer comparte esta perspectiva epistemológica, que, en su búsqueda de las diferencias y en sus objetivos de relativizar las formaciones, las sociales por ejemplo, marcha en sentido contrario a la igualdad, a lo fijo, a lo idéntico, preguntándose por las discontinuidades. Si bajo unas consideraciones, o en algunos aspectos, dos sistemas se parecen, en otros son diferentes, porque en cada cronotopo cada organización social es una y única. Donde se habla de lo único es una tautología decir que no se repite. Si preguntásemos por la Independencia de México, y nos contestaran con unas fórmulas abstractas sobre las condiciones de un país colonizado, sus luchas y su exitoso resultado liberador, sin especificar más, estariamos ante una respuesta históricamente impertinente: mientras más se limitaran las descripciones narrativas, más se traicionaría lo que esperamos de ellas. Decir "unicidad" es hablar de enfo-

${ }^{2}$ Karl R. Popper, La miseria del historicismo. Trad. de Pedro Schwartz. Madrid, Taurus, 1961, p. 130. (Ensayistas de Hoy)

${ }^{3}$ Hans-Georg Gadamer, Verdad y método. Fundamentos de una hermenéutica filosófica. Trad. de Ana Agud Aparicio y Rafael de Agapito. Salamanca, Sigueme, 1977, p. 363. (Hermeneia, 7 ) 
ques detallistas que construyen el tiempo, que narran los cambios del sistema en cuestión: unas luchas, unos enfrentamientos que ocurrieron en una organización social específica, la manera en que los comportamientos se potencializaron o anularon recíprocamente, y los éxitos y fracasos personales que tuvieron lugar en unas ocasiones y no en otras. Luego, dentro del paradigma sistémico, los acontecimientos son vistos como lo que ocurrió una vez, independientemente de si, en alguno de sus aspectos, pudo o podrá ocurrir en otras ocasiones. Adicionalmente, si en algunos aspectos dos procesos se parecen, en su composición total cada uno es uno y único.

Los procesos históricos son reconstruidos con base en los testimonios o textos, que son vistos, también, como un holon o sistema único. Mediante testimonios y estudios históricos sobre el cronotopo que analizará, el historiador parte de una organización social como un todo de imbricaciones estrechas, pasa a las partes y, con una serie de conjeturas interpretativas, regresa desde este nivel al todo: círculo hermenéutico que se rompe porque la investigación se realiza en fases: " $L a$ anticipación de sentido que hace referencia al todo sólo llega a una comprensión explícita a través del hecho de que las partes que se determinan desde el todo determinan a su vez a este todo". ${ }^{4}$ Partiendo de una vaga idea global de un proceso sistémico, el historiador lee los testimonios como una unidad de sentido, formula conjeturas y comprueba en el dicho mismo si se sostienen, o cómo han de afinarse, o si han de ser desechadas. Obviamente que su trabajo confronta múltiples testimonios y aun estudios históricos sobre el asunto en cuestión.

Ahora bien, el estructuralismo, que analizó las unidades de cada sistema por sus diferencias u oposiciones, se desentendió de la historia al abocarse a unos análisis sincrónicos: privilegió lo estable, el código, las reglas, bajo el supuesto de que es lo homogéneo, estable y colectivo, esto es, lo más inteligible comparado con los evanescentes, heterogéneos, individuales, diacrónicos y contingentes cambios; por ejemplo, para Saussure la langue explica la parole, o la lógica asociativa al acontecimiento o discurso mítico, para Lévi-Strauss. Para la hermenéutica, en cambio, el código tiene una realidad virtual, es una abstracción, mientras que el discurso o el habla existe, es el acontecimiento que ha de ser estudiado diacrónicamente, como tránsito, evolución, desarrollo. El enfoque diacrónico centrado en el acontecimiento, en el habla, en el discurso, se ocupa de la historia propiamente, y demanda a la historia que narre el tiempo como un juego entre memoria y su configuración desde un presente orientado mediante las expectativas de un futuro.

3.1. La historia -el cambio- y sus enfoques sistémicos fueron, según Gadamer, temas característicos del historicismo que, por lo mismo, pro-

${ }^{4}$ Ibid., p. 360. 
blematizó el mutuo copertenecerse de la realidad con el ser y el pensar; y, también, las abstracciones virtuales y ahistóricas del estructuralismo. Con la primera corriente filosófica mencionada y con su precedente, la hermenéutica filológica, se dio -afirma Heidegger- un salto al vacío que afianzó la "espiral hermenéutica" hacia la diferencia, que es percibida como la no presencia, la no estabilidad, la no fusión, la discrepancia; como la inestabilidad, los desniveles, los desequilibrios, la metaestabilidad, la no-identidad, el cambio, la disolución, la agonía, la vulnerabilidad, la opacidad de lo transitorio; y como aquello que es uno y único, y que reclama que se componga narrativamente su tiempo, que marchó desde el recuerdo de lo distinto a unas acciones que anticiparon una resolución (Austrag).

Frente a las epistemologías ahistóricas se hubo de cuestionar, dice Heidegger, los presupuestos de un pensamiento estrictamente re-presentativo, o fijado en unos mecanismos repetidos, o en taxonomías, o en códigos inamovibles para llegar a la onto-logía que descansa en el genitivo de la diferencia, o "ser de...", enunciación predicativa o apofántica sobre lo que se oculta y desoculta en los procesos de fractura de la historia.

Vista desde su propiedad diacrónica, la diferencia es eventualidad, epocalidad. Nosotros, los "seres para la muerte", o históricos, nos despedimos del pasado, de la tradición al asumirla como reto. La tradición no se fractura y desaparece, sino que se conserva como una cierta identidad. Identidad y diferencia son el juego entre la ruptura y la mismidad (das Selbe), que no es igualdad (das Gleiche), sino lo que permanece afirmado o negado en un curso histórico discontinuo: el ser por haber sido, es decir, un cúmulo de conocimientos, prácticas, de valores y orientaciones que configuran el presente, aunque van tomando diferentes cauces o direcciones y sufriendo cambios. "Mismidad" significa que el presente es, como decía Dilthey, un "microcosmos" en que espejea de muchas maneras el "macrocosmos", en tanto aquél porta las marcas de éste.

\section{II}

\section{Hermenéutica y sentido histórico}

En un corte sincrónico hay lo que Derrida llama différences, distinciones en lo contemporáneo, y diacrónicamente un diferir o différances, registrables en cada sujeto y en cualquier conjunto de sujetos como lo nuevo y lo transitorio que dejó sus huellas en su dilación por la vida. ${ }^{5}$

\footnotetext{
'Cf. J. Derrida, La différance. Marges de la philosophie. París, Minuit, 1972.
} 
El ser humano fue definido por Heidegger como Dasein, el ser-estar ahí. La eventualidad del ser, su discontinuidad, impone el sentido histórico, o saber que cada suceso forma parte de un curso temporal más amplio, lo cual, a su vez, impone al historiador la necesidad de hacer señalamientos cronotópicos, de usar coordenadas espacio-temporales: los agentes históricos están irremisiblemente adscritos a una situación, dentro de ciertos límites y, además, lo son, porque tales límites determinan sus horizontes, categoría que Gadamer toma de Husserl, Nietzsche y Dilthey. Dos contemporáneos y coterráneos pueden tomar recíprocamente conciencia del otro, del diferente, y, por retroefecto, del yo, en cada caso. En el diferir, cada yo es distinto del otro que vivió en el pasado, y del sí mismo que fue. Différance, que está encadenada a la sucesión del tiempo y al ser descrita narrativamente requiere que el estudioso dé razones históricas, que no sólo son los porqués de algo, sino que, por su carácter temporal, es decir, como modo de entender el devenir de los sucesos, abarcan, además del cuándo y el dónde, el cómo, el para qué y el contra qué. Los para qué y contra qué embonan dentro de esta tensión entre las vivencias pasadas y el presente gracias a un futuro que se anticipa, o sea, que se barrunta como una posible dirección del curso histórico.

En el ámbito filosófico, la fenomenología dejó de privilegiar las semejanzas, las presencias más o menos iguales; desde el historicismo, encabezado por Dilthey, y desde Heidegger, la "eventualidad" o "epocalidad", las persistentes discontinuidades y la vida como creación que sigue cursos inesperados, gracias a las múltiples acciones de los agentes históricos, a su praxis, incluyendo en ésta a sus discursos, a sus hablas, que chocan y se complementan con otras, son el núcleo temático de un nuevo intercambio dialógico interdisciplinario, donde la historia tiene un papel destacado porque, en unión con la narrativa literaria, siempre ha manejado un conciencia del cambio o de las différances y los modos de experimentarlas.

\section{En contra y a favor de la hermenéutica filológica}

En sentido estricto, la hermenéutica se ocupa de la interpretación del texto escrito, del testimonio, de las huellas o marcas, fijadas como un lenguaje, que hablan de la comprensibilidad de una interpretación y aquello a que ésta refiere o remite. Para que la nueva interpretación sea pertinente es menester, a juicio de Gadamer, rescatar, hasta cierto punto, la hermenéutica filológica -dentro de la cual cita ampliamente a Schleiermacher, tan influyente también en Dilthey-, o sea, volver a la "unidad interna de filología e historiografia", ${ }^{6}$ la que compromete al historiador a hacerse cargo de la

${ }^{\circ}$ H.-G. Gadamer, op. cit., p. 414. 
"literalidad originaria de lo dicho", 7 a saludar a éste guardando las distancias de la alteridad.

La filología aplica la "crítica documental" encargada de contextualizar, o "arte" de comprender (Verstehen), un plano expresivo dado para establecer su no explícito plano de contenido: descifra, pues, los significados o mensajes del texto como un holon o sistema. Las tareas de la crítica fueron divididas en: las concernientes al plano expresivo -o crítica externa-, que evita las no deseables intervenciones de impresores o copistas y demás fallas en las transcripciones; y en crítica interna, que aborda, muchas veces de forma cuestionable, las interferencias de la censura y la autocensura, las mentiras o el ocultamiento de información y hasta de los mensajes opuestos del texto, o de dos textos atribuidos a un mismo autor. Un valor testimonial, escribe Gadamer, depende de por quién y qué toma partido, de las convicciones con que aborda un asunto. Es, pues, menester entender más allá del sentido literal y frecuentemente en sentido opuesto al que pretende el texto. "El historiador interpreta las cosas en una dirección que el texto mismo no enuncia y que ni siquiera tiene por qué estar en su presunta orientación de sentido". ${ }^{9}$ El historiador se comporta en este aspecto como la hermenéutica jurídica, o el juez de instrucción en el interrogatorio. Para que llegue a buen fin, la hermenéutica ha de distinguir, también, los estilos de las expresiones y sus géneros de estilo. ${ }^{10}$ Así, por ejemplo, los compromisos de una narración literaria no son iguales a los de otra histórica, que trata de mantener, en la medida de lo posible, un principio de realidad fiel a lo acontecido, o sea, una correspondencia directa entre su dicho y lo acontecido, sin crear personajes o situaciones ficticias.

Gracias a la crítica, y a sus, por ejemplo, notas contextualizadoras, que salvan la distancia histórica, se llega a un acuerdo lingüistico sobre el discurso testimonial. Sin embargo, comprender el habla de un texto testimonial no agota las trabas que ha de vencer el historiador, sino que también debe llegar a un acuerdo con el mensaje, es decir, alcanzar lo que Gadamer llama, no sin ambigüedad, fusión de horizontes. Los testimonios son el medio que usa la historia para establecer los hechos, es decir, para llevar a cabo lo que Schleiermacher llamó "la reconstrucción histórica", que suple lo perdido, devolviendo al presente lo ocasional y originario que quedó en la tradición. Para el éxito de este quehacer el estudioso tiene que superar la precomprensión equivocada, o falsos prejuicios con que inició la interpre-

'Ibid., p. 462.

${ }^{8}$ Cf. Ibid., p. 409.

Ibid., p. 410.

${ }^{10}$ Cf. Ibid., p. 586. 
tación, y que la obstaculizaron, aunque también ha de saber que existen precomprensiones anticipadoras que no son malentendidos; ambos tipos de prejuicios son ineludibles para la comprensión" de la historia, que nunca deja de moverse en la cuerda floja entre los testimonios sobre unos acontecimientos desaparecidos y que, por lo mismo, no admiten constatación directa, y los variables horizontes de los historiadores. Para llegar a un acuerdo con el texto, o "ganar un horizonte", éstos han de tener una actitud abierta o dispuesta al aprendizaje, que, a su vez, implica que establezcan un diálogo: la distancia entre las opiniones o actitudes propias y ajenas es superable mediante una actitud, que Gadamer llama ser para el texto, ${ }^{12}$ ávida de consenso entre lo que dice literalmente el texto y que, quizás, después del acuerdo primero, llegue a un disenso interpretativo sobre los hechos. De tal ser para el texto depende el diálogo, caracterizado como la respetuosa conversación del estudioso hecha de preguntas abiertas a la opción "así o de otro modo", ${ }^{13}$ esto es, abiertas a que las respuestas confirmen o no los prejuicios con que anticipó la interpretación.

La comprensión no funde, no es una fusión ideológica: el hermeneuta "no necesita afirmar lo que está comprendiendo"; ${ }^{14}$ entender los testimonios del nazismo no equivale a coincidir con ellos. Ningún trabajo hermenéutico, y como tal, sistémico o histórico, interpreta sometiéndose al otro: se realiza desde unos horizontes con el fin de brincar la estrechez de los "panoramas". "Para el historiador es un supuesto fundamental que la tradición debe ser interpretada en un sentido distinto del que los textos pretenden por sí mismos". ${ }^{15}$

Gadamer se separó de la hermenéutica filológica porque ésta había con. fundido la labor crítica con la interpretación del historiador. La crítica contextualizadora es el paso inicial, tan sólo una condición de posibilidad de la Verstehen. Ejemplifico con las más de dos mil fichas léxicas, de derecho, costumbres, toponímicas... que hizo Rodríguez Marín a Don Quijote de la Mancha, a partir de las cuales creyó haber agotado las interpretaciones de la novela, y trató de desautorizar las que no se limitaran a aceptar la indicación cervantina de que fue escrita para solaz de espíritus mohínos. Luego, tales notas funcionan como un punto de partida para la comprensión pertinente, y tan sólo un punto de partida.

" Cf. Ibid., p. 369.

12 Ibid., p. 669.

${ }_{13}$ Ibid, , p. 439

14 Ibid., p. 660

15 rbid., p. 409. 


\section{Distancias con los prepuestos ahistóricos del historicismo}

Tampoco para Gadamer la comprensión histórica es la Einfühlung, defendida por el historicismo. Preciso que en cualquiera de sus acepciones, la comprensión es reconocerse en y por medio de algo; el intérprete camina del sí -yo sé, o creo esto y aquello- al para sí -me he enriquecido con esto y aquello que no creía ni sabía. Ahora bien, Dilthey intentó poner en pie, partiendo de la expresión, la vivencia del agente histórico. Las personas, dijo, se expresan dando cuerpo a sus vivencias, a un contenido espiritual -hecho de pensamientos y emociones- que el hermeneuta ha de volver a la vida. ${ }^{16}$ Ciertamente que sin esta forma de comprensión empática no podríamos entender al prójimo, ni tan siquiera estaríamos capacitados para sobrevivir, como puntualiza George Dévereux. ${ }^{17}$ No obstante, para descubrir las intenciones o el auténtico contenido espiritual de las expresiones de alguien se necesita una situación dialógica por excelencia, que los interlocutores se encuentren frente a frente y dialoguen entre sí. En cambio, a partir de un texto no podemos establecer con seguridad, por ejemplo, las verdaderas intenciones de su emisor: a quién exactamente tuvo en mente y con qué finalidad dijo lo que dijo. La comprensión del texto no es un retroceso a la conciencia o a la subjetividad del otro, el interlocutor perdido. No podemos retomar los motivos e ideas del agente histórico, sino que estamos constreñidos al texto, y a sus relaciones con otros textos. La historia no es psicología, sino que descifra lo que está establecido como expresión. El historiador no está capacitado, pues, para desplazarse hacia la constitución psíquica del agente histórico, o del autor del testimonio, sino que ha de tratar de poner en pie el horizonte que el escrito comunica: hacer valer la palabra.

\section{Excedente de sentido y la historia efectual}

Gadamer negó su apoyo al "historicismo trascendental"18 de cuño diltheyano o filológico: la hermenéutica descifra, escribió, pensamientos, y sus cargas afectivas, entendidos no como actos mentales, sino como aquello que comunica un testimonio, y que forzosamente será pensado desde otros horizontes. Para Gadamer, en La fenomenología del espíritu, Hegel matizó, subrayando su impotencia, la supuesta reconstrucción histórica asumida por

${ }^{16} \mathrm{Cf}$. Wilhelm Dilthey, El mundo histórico. Trad., rev., pról. y notas de Eugenio Ímaz. México, FCE, 1944. (Obras de Dilthey, 7 )

${ }^{17} \mathrm{Cf}$. George Dévereux, De la ansiedad al método en las ciencias del comportamiento. Prefacio de Weston La Barre, trad. de Félix Blanco. México, Siglo Xxi, 1977. (Teoría)

${ }^{18}$ H.-G. Gadamer, op. cit., p. 627. 
Schleiermacher y después, partiendo del ángulo psicologista, por Dilthey: las antiguas obras, escribió Hegel, son como un fruto arrancado del árbol; ahora ya no existen el árbol, ni los elementos que fueron su sustancia, ni el clima, ni... Con estas metáforas trató de establecer que las generaciones posteriores, que tratan de reconstruir lo ido, están en un "hacer exterior" que arrostra una "gota de lluvia" de aquel fruto. En otras palabras, ni la comprensión empática ni la crítica documental están capacitadas para reconstruir las intenciones que trató de dar el emisor a su texto, ni las que dio el agente a sus acciones: tal información se ha perdido, y, consiguientemente, el historiador ha de limitarse a una labor textual, contextual e intertextual.

Ahora bien, si la "conciencia hermenéutica" se basa en una conversación que se hace desde horizontes diferidos, debe estar abierta al hecho de que, dentro de los limites de la pertinencia, las respuestas de las expresiones a las preguntas que formulen los historiadores, y éstas mismas, jamás serán unidireccionales y univocas, excepto cuando sean "aparentes" o mera palabrería que obliga al estudioso a repetir la autoritaria "verdad".

En Las aventuras de la diferencia, Gianni Vattimo completa: la historia (la investigación de las cosas acontencidas) es la historia (lo acontecido) de mensajes, en la cual la respuesta no agota la apelación, porque depende de ella. En última instancia, la hermenéutica es la mediación de perspectivas móviles entre el testimonio o texto, lo que describe y explica y los cuestionamientos, que se fundamentan en las inacabables, en principio, interpretaciones de aquello que fue expresado. Toda interpretación se reinicia desde el excedente de sentido que aporta el historiador. Como media un excedente de visión entre los horizontes sucesivos, todos los historiadores están conminados a construir narrativamente el tiempo desde su propia tensión entre pasado o recuerdo, un presente en fuga y el porvenir que anticipan.

El gran error del historicismo fue que, confiado en su metodología, la sustrajo de su propia historicidad: olvidó la "colocación histórico-epocal" de las interpretaciones, ${ }^{19}$ que inevitablemente se realizan desde el humas de una demarcación histórica u horizonte, con sus "prejuicios fundamentales y sustentadores". ${ }^{20}$

La comunidad inicial o perspectiva de los testimonios - la gota de lluviaestá sometida a una continua reinterpretación, sin que pueda fijarse un punto final al respecto. Luego entonces, según la hermenéutica, como el texto depende de quienes lo interpretan, siempre está potencialmente inacabado:

"Gianni Vattimo, Las aventuras de la diferencia. Pensar después de Nietzsche y Heidegger. Trad. de Juan Carlos Gentile. Barcelona, Ediciones Peninsula, 1985, p. 169. (Historia, Ciencia y Sociedad)

${ }^{20}$ H.-G. Gadamer, op. cit., p. 365. 
los mismos procesos históricos que describe serán vistos desde sucesivas expectativas móviles. Las interpretaciones de la historia no las hace un observador neutral, o ajeno al mundo observado, sino un investigador participativo. La historia es, pues, de alguna manera, un radical presente, una historia interminable (según frase de Michael Ende).

El secreto para descifrar este enredo teórico es que el historiador pasa desde la cortedad de una supervaloración de lo que "cae más cerca"21 al "gran horizonte", negándose a "administrar el horizonte" propio como si fuera ajeno, o sea, que hay interpretaciones juiciosas o pertinentes, aunque, por juiciosas que sean, se formulan desde el "excedente de horizonte" de la historia efectual. Ejemplifico. Si, partiendo de un enfoque válido, el Liberalismo mexicano del siglo xx fue ponderado como la etapa modernizadora que acabó con el poder del clero, y como etapa "civilizatoria" de los "indios atrasados", hoy, cuando han sido cuestionadas las bases ideológicas del positivismo evolucionista, con que los hispanohablantes mexicanos justificaron el poder de dominio que ejercieron sobre los "indios", y contemplando desde otro horizonte los efectos que tuvo esta etapa, ha sido calificada, también válidamente, como etnocida: acabó con numerosas poblaciones mexicanas no-hispanohablantes. Hay un entendido adicional: esta manera de interpretar el Liberalismo decimonónico mexicano es formulada gracias a la expectativa de un futuro distinto, en el cual las distintas formaciones culturales puedan convivir en pie de igualdad. Así, el historiador incorpora en sus interpretaciones los efectos de las medidas que tomó el Liberalismo al "gran texto [...] del mundo que él más bien adivina". ${ }^{22}$ Mañana habrá otras aproximaciones interpretativas de este periodo. Por lo tanto, "Mal hermeneuta [es] el que crea que puede o debe quedarse con la última palabra" ${ }^{23}$

Resumo las últimas propuestas con una cita:

El objetivismo histórico que se remite a su propio método crítico oculta la trabazón efectual en la que se encuentra la misma conciencia histórica. Es verdad que gracias a su método crítico se sustrae a la arbitrariedad y capricho de ciertas actualizaciones del pasado, pero con esto se crea una buena conciencia desde la que niega aquellos presupuestos que no son arbitrarios ni caprichosos, sino sustentadores de todo su propio comprender. ${ }^{24}$

\footnotetext{
${ }^{21}$ Ibid., p. 373.

${ }^{22}$ Ibid., pp. 414-415

23. Ibid., p. 673.

${ }^{24}$ Ibid., p. 371.
} 